ORIGINAL RESEARCH

\title{
Acute Mountain Sickness Is Not Repeatable Across Two 12-Hour Normobaric Hypoxia Exposures
}

\author{
Martin J. MacInnis, BSc; Sarah Koch, MSc; Kristin E. MacLeod, BSc; Eric A. Carter, MSc; Radha Jain, BSc; \\ Michael S. Koehle, MD, PhD; Jim L. Rupert, PhD \\ From the School of Kinesiology (Mr MacInnis, Ms Koch, Ms MacLeod, Mr Carter, Ms Jain, and Drs Koehle and Rupert), and the Faculty of \\ Medicine (Dr Koehle), University of British Columbia, Vancouver, British Columbia, Canada.
}

\begin{abstract}
Objective.-The purposes of this experiment were to determine the repeatability of acute mountain sickness (AMS), AMS symptoms, and physiological responses across 2 identical hypoxic exposures.

Methods.-Subjects $(\mathrm{n}=25)$ spent 3 nights at simulated altitude in a normobaric hypoxia chamber: twice at a partial pressure of inspired oxygen $\left(\mathrm{P}_{\mathrm{I}_{\mathrm{O}}}\right)$ of $90 \mathrm{mmHg}$ (4000 m equivalent; "hypoxia") and once at a $\mathrm{P}_{\mathrm{I}_{2}}$ of $132 \mathrm{mmHg}$ (1000 m equivalent; "sham") with 14 or more days between exposures. The following variables were measured at hours 0 and 12 of each exposure: AMS severity (ie, Lake Louise score [LLS]), AMS incidence (LLS $\geq 3$ ), heart rate, oxygen saturation, blood pressure, and the fraction of exhaled nitric oxide. Oxygen saturation and heart rate were also measured while subjects slept.

Results.-The incidence of AMS was not statistically different between the 2 exposures (84\% vs $56 \%, P>.05$ ), but the severity of AMS (ie, LLS) was significantly lower on the second hypoxic exposure (mean [SD], 3.1 [1.8]) relative to the first hypoxic exposure $(4.8$ [2.3]; $P<.001)$. Headache was the only AMS symptom to have a significantly greater severity on both hypoxic exposures (relative to the sham exposure, $P<.05$ ). Physiological variables were moderately to strongly repeatable (intraclass correlation range 0.39 to 0.86$)$ but were not associated with AMS susceptibility $(P>.05)$.

Conclusions.-The LLS was not repeatable across 2 identical hypoxic exposures. Increased familiarity with the environment (not acclimation) could explain the reduced AMS severity on the second hypoxic exposure. Headache was the most reliable AMS symptom.
\end{abstract}

Key words: high altitude, reproducibility, acclimation, acclimatization, previous history

\section{Introduction}

Acute mountain sickness (AMS) is a relatively common form of altitude illness that can occur after rapid ascents to altitudes above $2500 \mathrm{~m}$ or during exposures to (normobaric or hypobaric) hypoxia in a laboratory. ${ }^{1}$ Humans vary significantly in their abilities to acclimatize to hypoxia, and researchers often use AMS as a marker of inadequate acclimatization or acclimation. ${ }^{1}$ Despite much research, the etiology of hypoxia intolerance is not well understood, ${ }^{2}$ and identifying persons who are susceptible to AMS before hypoxia exposure is difficult (eg, Barry and Pollard ${ }^{3}$ ).

Presented in part at the 18th International Hypoxia Symposium, February 26-March 3, 2013, Lake Louise, Alberta, Canada.

Corresponding author: Martin MacInnis, BSc, UBC School of Kinesiology, Room 210, 6081 University Boulevard, Vancouver, British Columbia V6T-1Z1, Canada (e-mail: martin@alumni.ubc.ca).
Repeatability is an assessment of consistency within persons over a series of measurements. ${ }^{4}$ Although a previous history of AMS is frequently stated to be a strong risk factor for the recurrence of AMS, ${ }^{3,5}$ evidence for the repeatability of AMS is not conclusive. Multiple studies reported associations between AMS history and AMS recurrence; ${ }^{6-8}$ however, these studies also reported moderate numbers of false positives (positive AMS history, negative AMS diagnosis) and false negatives (negative AMS history, positive AMS diagnosis), thus questioning the extent to which AMS is repeatable. Three prospective studies reported that AMS was repeatable, ${ }^{9-11}$ but hypoxic exposures were not necessarily comparable in 2 of the studies because of vasopressin use on 1 exposure $^{12}$ and a high likelihood of acclimatization on 1 exposure. ${ }^{10}$ Furthermore, the sample sizes were small $(<20)$ in 2 of the studies, 9,10 and all 3 lacked sham conditions to blind subjects to the conditions. 
The physiological processes responsible for individual differences in AMS susceptibility have yet to be determined, and a reliable physiological predictor of AMS remains elusive. ${ }^{13}$ Currently, results are inconsistent for associations between AMS and physiological variables such as blood oxygen saturation $\left(\mathrm{SpO}_{2}\right),{ }^{14,15}$ heart rate $(\mathrm{HR}),{ }^{16}$ blood pressure (BP), ${ }^{16,17}$ and the fraction of exhaled nitric oxide $\left(\mathrm{F}_{\mathrm{E}_{\mathrm{NO}}}\right){ }^{18,19}$ Establishing the repeatability of AMS in conjunction with the repeatability of these physiological variables should clarify which variables are associated with AMS and which are not.

This experiment was designed to determine the repeatability of AMS, AMS symptoms, and objective physiological variables across 2 identical normobaric hypoxia exposures. To prevent bias in self-reported AMS symptoms, a sham exposure was included in the experimental design and subjects were blinded to the experimental conditions. We hypothesized that individual physiological responses to hypoxia would be repeatable across the 2 identical hypoxic exposures and that each of the physiological variables would be associated with AMS.

\section{Methods}

\section{SUBJECTS}

Twenty-six healthy nonsmoking subjects (17 male; 9 female) were recruited, all of whom resided at low altitude (ie, $<200 \mathrm{~m}$ above sea level) and had not ascended above $2500 \mathrm{~m}$ (excluding commercial flights in pressurized airliners) in the 2 months preceding each exposure. Subjects were asked about their caffeine use, and those who acknowledged withdrawal symptoms from abstention were excluded because caffeine intake was restricted and symptoms of caffeine withdrawal can mimic symptoms of AMS. ${ }^{20}$ On their first visits to the laboratory, subjects were familiarized with the procedures and the testing environment. The Clinical Research Ethics Board of the University of British Columbia approved this study, and each subject provided written informed consent before participating.

\section{EXPERIMENTAL DESIGN}

This experiment utilized a single-blind, sham-controlled design. Subjects slept 3 nights in a normobaric hypoxia chamber (Colorado Altitude Training, Louisville, CO) located approximately $100 \mathrm{~m}$ above sea level at the University of British Columbia's Vancouver Campus. The chamber (approximate volume of $15.6 \mathrm{~m}^{3}$ ) was a transparent box housed in a large room with natural lighting. The temperature was controlled at $22^{\circ} \mathrm{C} \pm 3{ }^{\circ} \mathrm{C}$, but humidity was not controlled. Subjects were exposed to hypoxia on 2 occasions ( $\mathrm{H} 1$ and $\mathrm{H} 2$ ) with partial pressure of oxygen $\left(\mathrm{P}_{\mathrm{I}_{\mathrm{O}}}\right)$ of $90 \mathrm{mmHg}(4000 \mathrm{~m}$ equivalent $^{21}$ and to a sham condition on 1 occasion (SH) with $\mathrm{P}_{\mathrm{I}_{\mathrm{O}_{2}}}$ of $132 \mathrm{mmHg}$ (1000 m equivalent), ${ }^{21}$ with a minimum of 14 days between each exposure. The $\mathrm{P}_{\mathrm{I}_{2}}$ was measured with the chamber's built-in sensors, and airflow into the chamber was modified as necessary by the chamber to maintain the desired hypoxic dose. An exhaust fan vented the chamber to limit $\mathrm{CO}_{2}$ accumulation.

Subjects entered the chamber in the evening and remained in the chamber for 12 hours before exiting the next morning. Two subjects occupied the chamber simultaneously for most exposures, but a single subject occupied the chamber for 6 exposures owing to scheduling conflicts. Subjects were randomly divided into 3 groups, with each group experiencing $\mathrm{SH}$ on the first, second, or third exposure. Making the chamber slightly hypoxic for the $\mathrm{SH}$ exposure was necessary to mimic the sound of the hypoxic exposures. The $\mathrm{SH} \mathrm{P}_{\mathrm{I}_{\mathrm{O}_{2}}}$ did not lower the subjects' $\mathrm{SpO}_{2}$ values relative to baseline (although it would lower the partial pressure of oxygen in arterial blood) and AMS does not occur at $1000 \mathrm{~m} .{ }^{1}$ Subjects were blinded to the conditions, but the researchers were not because $\mathrm{Spo}_{2}$ values needed to be monitored as a safety precaution.

To limit confounding effects on various measurements, subjects were asked to refrain from the intake of food and drink for 2 hours, caffeine for 12 hours, alcohol for 24 hours, and food rich in nitrates for 48 hours before entering the chamber. ${ }^{22}$ Subjects ingested water ad libitum in the chamber and were offered a standard meal after 1 hour. While in the chamber, subjects rested (ie, performed no physical activity).

\section{PHYSIOLOGICAL MEASUREMENTS}

All variables were measured in room air before subjects entered the chamber (hour 0) and inside the chamber before subjects exited (hour 12). Subjects were awoken 30 minutes before exiting the chamber to allow for data collection.

Hypoxia tolerance was assessed using the Lake Louise score (LLS) questionnaire, ${ }^{23}$ which required subjects to rate 5 symptoms of AMS (headache, gastrointestinal symptoms, fatigue, dizziness, and sleep difficulty) on a scale of 0 (not present) to 3 (severe). A LLS of 3 or greater with a headache score of 1 or greater was considered a positive diagnosis (AMS+), and a LLS not meeting these criteria was considered a negative diagnosis (AMS-) ${ }^{23}$ 
While subjects were supine, $\mathrm{HR}$ and $\mathrm{Spo}_{2}$ were measured from the ear lobe with a tabletop pulse oximeter (Avant 9600; Nonin Instruments, Plymouth, $\mathrm{MN})$. Both variables were recorded continuously for 5 minutes, and the mean of each recording was analyzed. With the subjects still supine, systolic blood pressure (SBP) and diastolic blood pressure (DBP) were measured with a BPM-200 automated blood pressure monitor (BpTRU; Coquitlam, BC, Canada). The average of 3 measurements was analyzed. Mean arterial pressure (MAP) was estimated as $2 / 3 \mathrm{DBP}+1 / 3 \mathrm{SBP}$. The $\mathrm{F}_{\mathrm{E}_{\mathrm{NO}}}$ was measured using a NIOX MINO handheld electrochemical analyzer (Aerocrine AB, Solna, Sweden) according to the manufacturer's recommendations and the established guidelines. ${ }^{24}$ The $\mathrm{F}_{\mathrm{E}_{\mathrm{NO}}}$ was measured once at hour 0 and once at hour 12. Normobaric hypoxia does not affect the accuracy of this device. ${ }^{25}$

Nocturnal HR and $\mathrm{SpO}_{2}$ were measured continuously while subjects slept using pulse oximetry (as described above). Six-hour blocks of data (corresponding to hours 5 to 11 , the hours during which subjects were most likely to be sleeping) were analyzed for each subject during each exposure. From these data, the 6-hour means for $\mathrm{HR}$ and $\mathrm{SpO}_{2}$ were calculated, and the proportion of time elapsed below $\mathrm{SpO}_{2}$ thresholds (ie, time below $70 \%$ $\mathrm{SpO}_{2}$, time below $75 \% \mathrm{Spo}_{2}$, and so forth) were calculated.

\section{DATA ANALYSIS}

Data analysis was performed using SPSS version 21.0 (IBM, Armonk, NY), and alpha was set to 0.05 for all statistical tests.

The severity of AMS and the severity of each individual AMS symptom during each condition (at hour 12) were compared with a one-way analysis of variance (ANOVA) and Friedman tests, respectively. Post hoc analysis was performed with Bonferroni-corrected paired samples $t$ tests and Wilcoxon signed rank tests, respectively. The exact McNemar's test was used to compare the incidence of AMS and its symptoms across exposures. The percent agreement ${ }^{26}$ was calculated as a measure of repeatability. To determine if familiarity with the chamber affected the LLS, tests for linear trends were performed (independent variable, condition; dependent variable, LLS).

The effect of the condition on each continuous physiological variable was determined using a two-way repeated measures ANOVA (time [0 and 12 hours] vs condition $[\mathrm{H} 1, \mathrm{H} 2, \mathrm{SH}])$. Post hoc analysis was performed with Bonferroni-corrected paired samples $t$ tests within each exposure and across exposures at hour 12 . The effect of condition on mean nocturnal $\mathrm{HR}$ and $\mathrm{SpO}_{2}$ was determined with one-way repeated measures ANOVA and a similar post hoc analysis. The repeatability of each physiological variable was measured with an intraclass correlation (ICC), and the association between physiological variables and AMS was tested with independent $t$ tests.

\section{Results}

\section{SUBJECT CHARACTERISTICS}

Twenty-five subjects ( 9 female and 16 male) completed this experiment, and 1 male subject withdrew from the study after completing 2 exposures. The mean (SD) age of subjects was 24.6 years (6.2 years), mean height was $175 \mathrm{~cm}(8.4 \mathrm{~cm})$, and mean weight was $72 \mathrm{~kg}(12 \mathrm{~kg})$. One subject's $\mathrm{F}_{\mathrm{E}_{\mathrm{NO}}}$ data were excluded from analysis because she exhaled more than 100 parts per billion (ppb), approximately 5 times larger than the mean, and high $\mathrm{F}_{\mathrm{E}_{\mathrm{NO}}}$ can indicate the presence of asthma, ${ }^{27}$ which was an exclusion criterion for the $\mathrm{F}_{\mathrm{E}_{\mathrm{NO}}}$ component of the study. After 8 subjects had begun the experiment, BP measurements were added as outcome variables $(n=17$ for these variables). Consecutive exposures were separated by a median of 21 days (14-108 days), and H1 and H2 were separated by a median of 28 days (14-138 days).

\section{NORMOBARIC CHAMBER CONDITIONS}

A mean $\mathrm{P}_{\mathrm{I}_{2}}$ of $90 \mathrm{mmHg}$ (87-93 mmHg) was maintained for all hypoxic exposures, and a mean $\mathrm{P}_{\mathrm{I}_{2}}$ of $132 \mathrm{mmHg}(129-135 \mathrm{mmHg})$ was maintained for sham exposures. The partial pressure of carbon dioxide $\left(\mathrm{PCO}_{2}\right)$ was not measured during each exposure; however, multiple measurements made during the study demonstrated that the chamber maintained the $\mathrm{PCO}_{2}$ below $2.6 \mathrm{mmHg}$ in hypoxic and sham conditions.

\section{REPEATABILITY OF AMS AND ITS SYMPTOMS}

The incidence and severity of AMS were much greater in both hypoxic exposures ( $\mathrm{H} 1$ and $\mathrm{H} 2$ ) compared to the SH exposure (Table 1, Figure 1). The severity of AMS was significantly lower $(-35 \%)$ in $\mathrm{H} 2$ relative to $\mathrm{H} 1$ $(P<.001 ;$ Table 1$)$, but the difference in the incidence of AMS from $\mathrm{H} 1$ to $\mathrm{H} 2$ (also $-35 \%$ ) was not statistically significant $(P=.065)$. Agreements for the incidence and severity of AMS on $\mathrm{H} 1$ and $\mathrm{H} 2$ were low (Table 1).

The incidence and severity of all 5 individual symptoms comprising the LLS were significantly greater in $\mathrm{H} 1$ relative to $\mathrm{SH}$, but only the incidence and severity of headache symptoms were significantly greater in $\mathrm{H} 2$ relative to $\mathrm{SH}$ (Table 1). Agreements for the incidence and severity of AMS symptoms were variable (Table 1). 
Table 1. Incidence and severity of acute mountain sickness and its individual symptoms in 1 sham and 2 normobaric hypoxia exposures

\begin{tabular}{|c|c|c|c|c|c|c|c|c|}
\hline \multirow[b]{2}{*}{ Symptom } & \multicolumn{4}{|c|}{ Incidence } & \multicolumn{4}{|c|}{ Severity } \\
\hline & $S H^{a}$ & $H 1^{a}$ & $H 2^{a}$ & Agreement $^{b}$ & $S H^{c}$ & $H 1^{c}$ & $H 2^{c}$ & Agreement $^{b}$ \\
\hline Headache & $3(12)$ & $21(84)^{d}$ & $19(76)^{d}$ & $16(68)$ & $0(0-1)$ & $2(0-3)^{d}$ & $1(0-2)^{d}$ & $8(32)$ \\
\hline Gastrointestinal & $0(0)$ & $6(24)^{d}$ & $1(4)^{e}$ & $20(80)$ & $0(0)$ & $0(0-2)^{d}$ & $0(0-1)^{e}$ & $20(80)$ \\
\hline Fatigue & $4(16)$ & $14(56)^{d}$ & $5(20)^{e}$ & $16(64)$ & $0(0-1)$ & $1(0-2)^{d}$ & $0(0-2)^{e}$ & $14(56)$ \\
\hline Dizziness & $2(8)$ & $9(36)^{d}$ & $6(24)$ & $18(72)$ & $0(0-1)$ & $0(0-2)^{d}$ & $0(0-2)$ & $17(68)$ \\
\hline Sleep difficulty & $18(72)$ & $24(96)^{d}$ & $22(88)$ & $23(92)$ & $1(0-2)$ & $2(0-3)^{d}$ & $1(0-3)$ & $12(48)$ \\
\hline AMS & $1(4)$ & $21(84)^{d}$ & $14(56)^{d}$ & $14(56)$ & $1.2(1.0)$ & $4.8(2.3)^{d}$ & $3.1(1.8)^{d, e}$ & $4(16)$ \\
\hline
\end{tabular}

${ }^{a}$ The number (percentage) of subjects who had each symptom and acute mountain sickness (AMS).

${ }^{b}$ The number (percentage) of subjects who had the same response on first hypoxia exposure (H1) and second hypoxia exposure (H2).

${ }^{c}$ For individual symptoms, the median (range) is reported; for AMS, the mean (SD) is reported.

${ }^{d}$ Significant difference from the sham exposure (SH).

${ }^{e}$ Significant difference between the 2 hypoxic conditions.

The incidence and severity of headache were not statistically different between $\mathrm{H} 1$ and $\mathrm{H} 2$ (Table 1).

The decrease in LLS across SH exposures was not statistically significant $(P=.066)$, but the linear trend for a decrease in sleep difficulty scores was statistically significant $(P=.025$; Figure 2$)$.

\section{REPEATABILITY OF PHYSIOLOGICAL RESPONSES TO HYPOXIA}

As shown in Table 2, $\mathrm{SpO}_{2}$ was significantly decreased by hypoxia; HR, DBP, and MAP were significantly increased by hypoxia; and $\mathrm{F}_{\mathrm{E}_{\mathrm{NO}}}$ and $\mathrm{SBP}$ were unaffected by hypoxia. At hour 12, the means of each physiological variable were not statistically different in $\mathrm{H} 1$ and $\mathrm{H} 2$

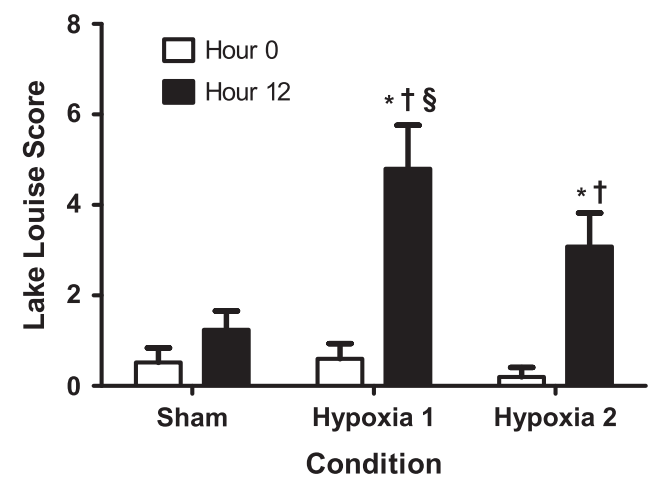

Figure 1. The Lake Louise score at hour 0 (open bars) and hour 12 (solid bars) of the sham, first hypoxic, and second hypoxic exposures $\left(\mathrm{P}_{\mathrm{I}_{\mathrm{O}_{2}}}\right.$ was $132 \mathrm{mmHg}, 90 \mathrm{mmHg}$, and $90 \mathrm{mmHg}$, respectively). *Denotes a 12 -hour mean that was significantly greater than the 0 hour mean of the same condition $(P<.05)$. $\dagger$ Denotes a 12-hour mean that was significantly greater than the 12 -hour sham mean $(P<.05)$. $\S$ Denotes a 12 -hour mean that was significantly greater than the 12 hour mean of the second hypoxia exposure $(P<.05)$. Error bars represent $1 \mathrm{SD}$ of the mean, and $\mathrm{n}=25$.
(Table 2). The ICC of physiological variables at hour 12 ranged from 0.39 to 0.84 , indicating moderate to strong repeatability in normobaric hypoxia (Table 2).

Nocturnal HR was greater on H1 (63.2 [10.6] beats/ $\mathrm{min})$ and $\mathrm{H} 2(60.1$ [11.5] beats $/ \mathrm{min})$ relative to $\mathrm{SH}(52.5$ [9.1] beats/min; $P<.001$ for both comparisons); and nocturnal HR was greater on $\mathrm{H} 1$ compared to $\mathrm{H} 2(P=$ .005). Relative to $\mathrm{SH}\left(97.5 \%\right.$ [1.5\%]), nocturnal $\mathrm{Spo}_{2}$ was lower on $\mathrm{H} 1$ (79.4\% [4.6\%]; $P<.001)$ and $\mathrm{H} 2$ (80.2\% [4.7\%]; $P<.001)$; however, nocturnal $\mathrm{Spo}_{2}$ was similar on $\mathrm{H} 1$ and $\mathrm{H} 2(P=.14)$. The ICC of nocturnal $\mathrm{HR}$ and nocturnal $\mathrm{SpO}_{2}$ were 0.86 and 0.68 , respectively $(P<.05$ for both).

\section{PREDICTING AND DIAGNOSING AMS}

Twelve subjects were AMS+/AMS+, 2 subjects were AMS-/AMS-, 9 subjects were AMS+/AMS-, and 2 subjects were AMS-/AMS+ on $\mathrm{H} 1$ and $\mathrm{H} 2$, respectively; therefore, the AMS diagnosis on $\mathrm{H} 1$ had a sensitivity of $86 \%$, a specificity of $18 \%$, a positive predictive value of $56 \%$, and a negative predictive value of $50 \%$ for the AMS status on $\mathrm{H} 2$.

The AMS+ and AMS - subjects' data were only compared on $\mathrm{H} 2$ because the distribution of subjects was unbalanced on H1 (ie, 21 AMS+, 4 AMS- on H1). None of the physiological variables was significantly associated with AMS (Table 3). The mean proportion of time elapsed below each $\mathrm{Spo}_{2}$ threshold was similar for AMS+ and AMS- subjects, and nocturnal $\mathrm{SpO}_{2}$ was not associated with LLS (Figure 3).

\section{Discussion}

This is the first experiment to assess AMS repeatability with a single blind, sham-controlled design. Contrary to 

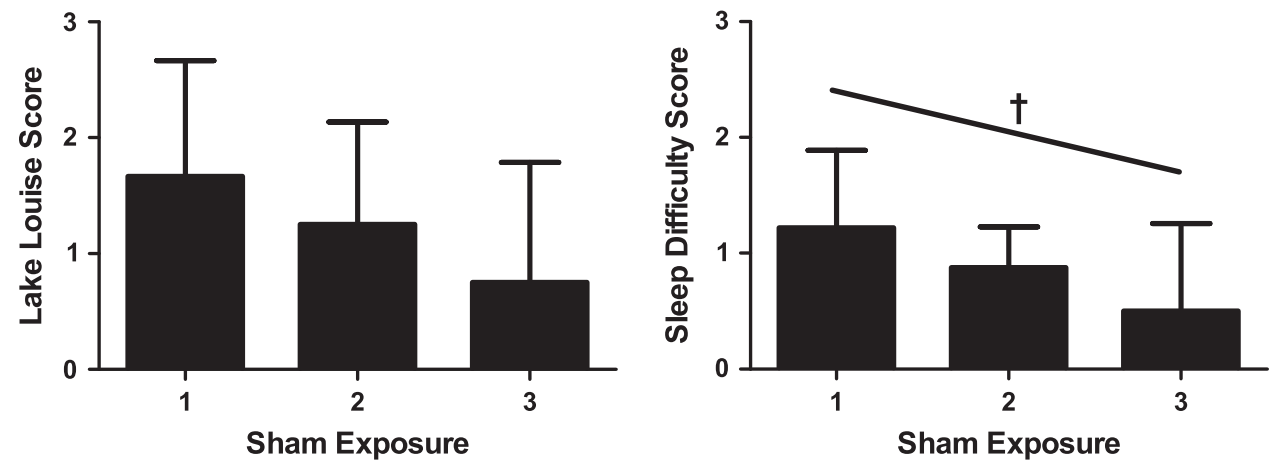

Figure 2. The mean Lake Louise score (left) and sleep difficulty item score (right) from hour 12 of sham conditions that randomly occurred on the first $(n=8)$, second $(n=8)$, or third $(n=9)$ exposure of the study. Error bars represent 1 SD of the mean. $\dagger$ Denotes a statistically significant linear trend for decreasing sleep difficulty scores $(P=.025)$. The linear trend for the Lake Louise Score was not statistically significant $(P=.066)$.

our hypotheses, the severity of AMS (measured with the LLS) was lower on the second hypoxic exposure relative to the first, and none of the physiological variables was associated with AMS. As hypothesized, however, physiological variables were moderately to strongly repeatable across $\mathrm{H} 1$ and $\mathrm{H} 2$. We suggest that familiarization with the environment may be responsible for the decrease in AMS symptom severity across hypoxic exposures.

The difference in the AMS incidence between $\mathrm{H} 1$ and $\mathrm{H} 2$ was not statistically significant; however, that the severity of AMS was significantly lower in $\mathrm{H} 2$ still suggests that AMS was not repeatable in this experiment.

Table 2. Physiological responses to one 12-hour sham exposure and two 12-hour hypoxia exposures

\begin{tabular}{|c|c|c|c|c|c|c|}
\hline \multirow{2}{*}{ Variable } & \multirow{2}{*}{ Condition } & \multirow{2}{*}{$n$} & \multicolumn{2}{|c|}{ Time } & \multirow{2}{*}{ Change $(\%)^{a}$} & \multirow{2}{*}{$I C C^{b}$} \\
\hline & & & Hour 0 & Hour 12 & & \\
\hline \multirow[t]{3}{*}{$\mathrm{HR}$, beats/min } & $\mathrm{SH}$ & 25 & $62.4(10.3)$ & $55.2(11.3)^{c}$ & -11.5 & \\
\hline & $\mathrm{H} 1$ & 25 & $62.3(9.54)$ & $64.5(12.5)^{d}$ & +3.5 & \\
\hline & $\mathrm{H} 2$ & 25 & $63.3(9.88)$ & $62.0(13.5)^{d}$ & +2.1 & $0.84^{c}$ \\
\hline \multirow{3}{*}{$\mathrm{Spo}_{2}, \%$} & SH & 25 & $97.9(1.15)$ & $98.0(1.02)$ & +0.0 & \\
\hline & $\mathrm{H} 1$ & 25 & $98.3(1.32)$ & $84.7(4.67)^{c, d}$ & -13.9 & \\
\hline & $\mathrm{H} 2$ & 25 & $98.1(1.20)$ & $84.8(5.18)^{c, d}$ & -13.6 & $0.39^{c}$ \\
\hline \multirow[t]{3}{*}{$\mathrm{F}_{\mathrm{E}_{\mathrm{NO}}}, \mathrm{ppb}$} & SH & 24 & $21.6(8.16)$ & $21.8(7.65)$ & +0.9 & \\
\hline & $\mathrm{H} 1$ & 24 & $21.6(10.8)$ & $22.0(8.66)$ & +1.9 & \\
\hline & $\mathrm{H} 2$ & 24 & $22.1(9.03)$ & $23.8(9.17)$ & +7.7 & $0.78^{c}$ \\
\hline \multirow[t]{3}{*}{$\mathrm{SBP}, \mathrm{mmHg}$} & SH & 17 & 109.2 & $106.7(10.6)$ & -2.3 & \\
\hline & $\mathrm{H} 1$ & 17 & $108.1(9.12)$ & $109.1(7.85)$ & +0.9 & \\
\hline & $\mathrm{H} 2$ & 17 & $105.2(8.10)$ & $107.8(8.74)$ & +2.5 & $0.65^{\circ}$ \\
\hline \multirow[t]{3}{*}{$\mathrm{DBP}, \mathrm{mmHg}$} & SH & 17 & $64.7(5.35)$ & $64.5(7.29)$ & -0.3 & \\
\hline & $\mathrm{H} 1$ & 17 & $63.9(5.26)$ & $69.0(4.78)^{c, d}$ & +8.0 & \\
\hline & $\mathrm{H} 2$ & 17 & $62.3(4.40)$ & $67.0(7.33)^{C}$ & +7.5 & $0.57^{c}$ \\
\hline \multirow[t]{3}{*}{ MAP, mmHg } & $\mathrm{SH}$ & 17 & $79.6(6.49)$ & $78.4(7.76)$ & -1.5 & \\
\hline & $\mathrm{H} 1$ & 17 & $78.8(5.53)$ & $82.2(5.34)^{c, d}$ & +4.3 & \\
\hline & $\mathrm{H} 2$ & 17 & $76.6(4.69)$ & $80.6(6.51)^{c}$ & +5.2 & $0.66^{c}$ \\
\hline
\end{tabular}

Data are presented as mean (SD).

$\mathrm{HR}$, heart rate; $\mathrm{SpO}_{2}$, oxygen saturation; $\mathrm{F}_{\mathrm{E}_{\mathrm{NO}}}$, fraction of exhaled nitric oxide; ppb, parts per billion; $\mathrm{SBP}$, systolic blood pressure; DBP, diastolic blood pressure; MAP, mean arterial pressure.

${ }^{a}$ The percent change is calculated for hour 12 relative to hour 0 of the same exposure.

${ }^{b}$ Intraclass correlations (ICC) are calculated for mean values measured at hour 12 of the first hypoxia exposure (H1) and second hypoxia exposure (H2).

${ }^{c}$ Statistically different from hour 0 in the same exposure after Bonferroni correction $(P<.008)$.

${ }^{d}$ Statistically different from hour 12 of sham exposure $(\mathrm{SH})$ after Bonferroni correction $(P<.008)$.

${ }^{e}$ Statistically significant ICC at hour 12 of $\mathrm{H} 1$ and $\mathrm{H} 2(P<.05)$. 
Table 3. Physiological responses to the second 12-hour normobaric hypoxia exposure in subjects with and subjects without acute mountain sickness

\begin{tabular}{|c|c|c|c|c|c|c|}
\hline Variable & $n$ & Time (hour) & $A M S-$ & $A M S+$ & $T$ statistic & $P$ value \\
\hline $\mathrm{HR}$, beats/min & 25 & 0 & $60.9(9.1)$ & $65.1(10.4)$ & -1.05 & .31 \\
\hline $\mathrm{HR}$, beats/min & 25 & $5-11$ & $57.0(10.1)$ & $62.5(12.3)$ & -1.19 & .25 \\
\hline $\mathrm{HR}$, beats/min & 25 & 12 & $58.4(12.0)$ & $64.9(14.4)$ & -1.20 & .24 \\
\hline $\mathrm{Spo}_{2}, \%$ & 25 & 0 & $98.2(1.1)$ & $98.0(1.3)$ & 0.46 & .65 \\
\hline $\mathrm{SpO}_{2}, \%$ & 25 & $5-11$ & $79.8(4.0)$ & $80.6(5.3)$ & -0.40 & .69 \\
\hline $\mathrm{SpO}_{2}, \%$ & 25 & 12 & $85.5(2.8)$ & $84.2(6.5)$ & 0.65 & .52 \\
\hline $\mathrm{F}_{\mathrm{E}_{\mathrm{NO}}}, \mathrm{ppb}$ & 24 & 0 & $24.8(10.4)$ & $19.8(7.4)$ & 1.37 & .19 \\
\hline $\mathrm{F}_{\mathrm{E}_{\mathrm{NO}}}, \mathrm{ppb}$ & 24 & 12 & $25.7(9.9)$ & $22.1(8.5)$ & 0.97 & .34 \\
\hline $\mathrm{SBP}, \mathrm{mmHg}$ & 17 & 0 & $105.0(7.5)$ & $105.3(8.8)$ & -0.06 & .95 \\
\hline $\mathrm{SBP}, \mathrm{mmHg}$ & 17 & 12 & $106.8(8.7)$ & $108.4(9.1)$ & -0.34 & .74 \\
\hline $\mathrm{DBP}, \mathrm{mmHg}$ & 17 & 0 & 60.7 (4.6) & $63.2(4.2)$ & -1.14 & .27 \\
\hline $\mathrm{DBP}, \mathrm{mmHg}$ & 17 & 12 & $65.0(6.7)$ & $68.1(7.7)$ & -0.82 & .42 \\
\hline MAP, mmHg & 17 & 0 & $75.4(5.5)$ & $77.2(4.3)$ & -0.73 & .48 \\
\hline MAP, mmHg & 17 & 12 & $79.2(5.3)$ & $81.5(7.1)$ & -0.68 & .50 \\
\hline
\end{tabular}

Data are presented as mean (SD).

AMS-, without acute mountain sickness; AMS+, with acute mountain sickness; HR, heart rate; $\mathrm{Spo}_{2}$, oxygen saturation; $\mathrm{F}_{\mathrm{E}_{\mathrm{No}}}$, fraction of exhaled nitric oxide; ppb, parts per billion; SBP, systolic blood pressure; DBP, diastolic blood pressure; MAP, mean arterial pressure.

The severity of AMS is more sensitive to changes than the incidence of AMS, making it a better index for repeatability: for any decrease in LLS, whether a change in AMS incidence would occur is dependent on 1) the threshold LLS for a positive AMS diagnosis, and 2) the mean severity of AMS induced by the experimental conditions. The lack of repeatability suggests that it may be inappropriate to categorize subjects as AMS susceptible or AMS resistant after 1 hypoxia exposure.

Headache, the cardinal symptom of $\mathrm{AMS},{ }^{28}$ was the only symptom with a significantly greater incidence and severity in $\mathrm{H} 1$ and $\mathrm{H} 2$ relative to $\mathrm{SH}$. The incidence and severity of headache were not statistically different in $\mathrm{H} 1$ and $\mathrm{H} 2$, suggesting that headache symptoms may be influenced less by familiarization than other AMS symptoms. Sleep difficulty was the only other symptom that occurred commonly on $\mathrm{H} 2$, but the elevated sleep-difficulty scores in SH suggest that the chamber (independent of hypoxia) was responsible for much of the difficulty sleeping.

The decrease in LLS from H1 to H2 was not likely due to hypoxia acclimation. Although 5 days above 3000 $\mathrm{m}$ in the 2 months preceding an ascent to $4559 \mathrm{~m}$ decreased the risk of AMS, ${ }^{7}$ to our knowledge, sustained acclimation multiple weeks after a single 12-hour exposure to hypoxia has not been demonstrated (in awake or sleeping subjects). A washout period similar to the one employed in this study (ie, 12-14 days) was previously used to prevent carryover effects between 2 longer (22-hour) hypoxic exposures (barometric pressure
$446 \mathrm{mmHg} ; 4300 \mathrm{~m}$ equivalent). ${ }^{29}$ That objective physiological responses were similar to $\mathrm{H} 1$ and $\mathrm{H} 2$ also suggests subjects were not acclimated to hypoxia on the second hypoxic exposure.

Our data suggest that familiarization to the environment affects the LLS, and our results reaffirm the subjective nature of the LLS. An unfamiliar sleeping environment and the anticipation of unpleasant symptoms (the potential symptoms of AMS were a required element of the consent forms) may have been responsible for the greater LLS on H1. MacNutt et $\mathrm{al}^{30}$ suggested that a greater "psychological tolerance" of altitude (acquired from previous ascents) could explain the reduced AMS symptoms observed in subjects reascending to altitude. Although our subjects did not ascend to altitude, they may have been anxious about the experiment. In support of this suggestion, sleep quality improved significantly with the number of previous exposures to the chamber, and mean HR, SBP, DBP, and MAP were slightly lower in $\mathrm{H} 2$ compared with $\mathrm{H} 1$ (at hour 12), possibly indicating reduced anxiety. Although familiarization with the environment has been postulated to be a potential confounding variable in studies of this sort, ${ }^{29}$ this study is the first to demonstrate that familiarization with the testing environment affects self-reported LLS.

That AMS severity was not repeatable is in disagreement with previous studies, ${ }^{9-11}$ but between-study comparisons are difficult for a number of reasons. Firstly, only 1 previous study ${ }^{11}$ used the LLS questionnaire, and 

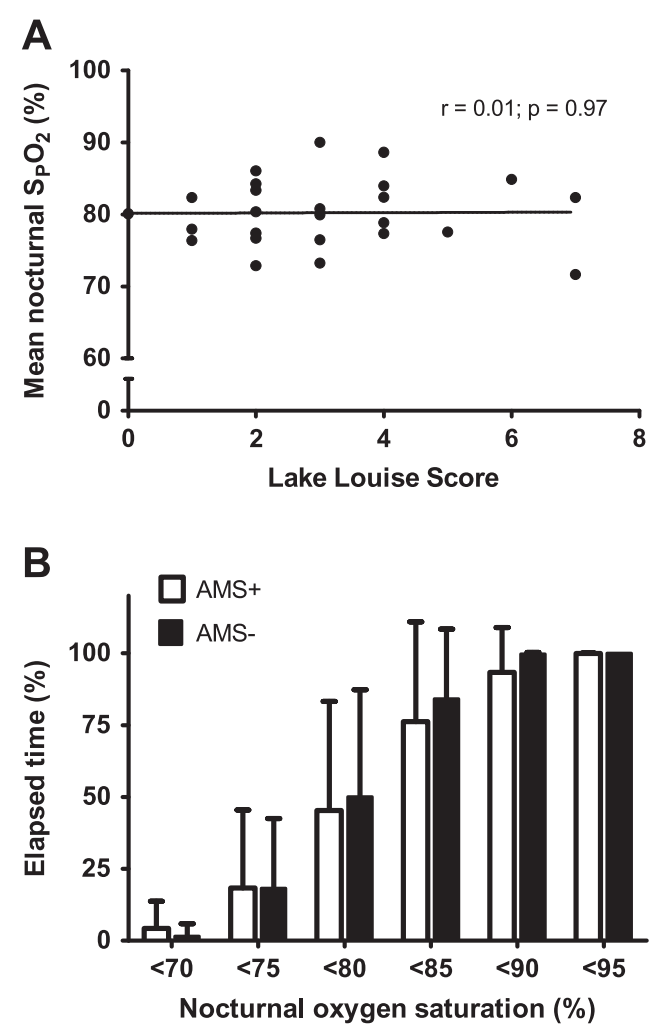

Figure 3. Nocturnal oxygen saturation $\left(\mathrm{Spo}_{2}\right)$ of subjects during the second hypoxic exposure. (A) The relationship between the mean $\mathrm{SpO}_{2}$ and the Lake Louise score on the second hypoxic exposure. (B) The percentage of time elapsed below thresholds of $\mathrm{Spo}_{2}$ for subjects with acute mountain sickness (AMS+ [open bars]) and subjects without acute mountain sickness (AMS- [solid bars]). Error bars represent 1 $\mathrm{SD}$ of the mean, and $\mathrm{n}=25$.

methods of assessing AMS (eg, Hackett's score ${ }^{31}$ ) used in the other studies will likely have different psychometric properties compared to the LLS that will affect repeatability. Secondly, the methods used to calculate or confirm AMS repeatability differed substantially across studies, preventing a direct comparison of quantitative repeatability statistics. Thirdly, methodological differences make direct comparisons problematic because 2 studies occurred at high altitude, ${ }^{10,11} 1$ study utilized a hypobaric chamber, ${ }^{9}$ and our study was conducted in a normobaric chamber. It is possible that there would a greater effect of familiarization in a chamber experiment than in a highaltitude experiment because sleeping in a chamber would be a novel experience for the subjects, whereas sleeping in a high-altitude setting could be similar to sleeping in a low-altitude setting in many ways. Finally, we included the $\mathrm{SH}$ exposure to reduce subject bias, which was not done in any of the previous studies.

Pulse oximetry is frequently used in field studies of AMS, but pulse oximetry has not been conclusively demonstrated to be a reliable diagnostic tool for AMS. ${ }^{32}$ Mean HR (wakeful) was highly repeatable in this study, but similar to previous studies (eg, Wagner et $\mathrm{al}^{33}$ ), HR was not associated with AMS. The mean $\mathrm{Spo}_{2}$ (wakeful) had the lowest repeatability, and it was also not associated with AMS. Our $\mathrm{SpO}_{2}$ results are in agreement with some studies, ${ }^{15,33}$ but not with others that showed AMS+ subjects to have lower $\mathrm{SpO}_{2}$ values than AMS - subjects. ${ }^{14,34}$ The low repeatability of wakeful $\mathrm{SpO}_{2}$ may explain mixed results in the literature. As $\mathrm{HR}$ is strongly affected by physical exertion and $\mathrm{SpO}_{2}$ is strongly influenced by voluntary breathing patterns, ${ }^{35}$ Windsor $^{32}$ proposed that pulse oximetry data collected during sleep may be more informative than data collected during wakefulness; however, our results demonstrated that, although nocturnal $\mathrm{HR}$ and $\mathrm{SpO}_{2}$ were repeatable, neither variable was associated with AMS. This finding conflicts with previous studies that reported a lower mean nocturnal $\mathrm{Spo}_{2}$ in $\mathrm{AMS}+$ subjects relative to AMS- subjects. $^{36,37}$

In addition to pulse oximetry, we tested $\mathrm{BP}$ and $\mathrm{F}_{\mathrm{E}_{\mathrm{NO}}}$ for associations with AMS. Blood pressure was not associated with AMS, but our sample size was relatively small $(n=17)$ for these comparisons. The ICCs of SBP, DBP, and MAP were lower than those measured in normoxia, ${ }^{38}$ possibly because of the small range of each variable in our data. ${ }^{39}$ The $\mathrm{F}_{\mathrm{E}_{\mathrm{NO}}}$ was unaffected by normobaric hypoxia, a finding that supports previous studies, ${ }^{19,25,40}$ and the high repeatability of $\mathrm{F}_{\mathrm{E}_{\mathrm{NO}}}$ agrees with data collected in normoxia. ${ }^{41}$ The AMS+ subjects had a lower mean $\mathrm{F}_{\mathrm{E}_{\mathrm{NO}}}$ than the AMS- subjects, which, although not statistically significant $(P=.065)$, is consistent with previous studies. ${ }^{19,42}$

\section{STUDY LIMITATIONS}

There are several limitations to this experiment that should be considered when interpreting our results. Firstly, we cannot rule out the possibility that a consistent history of AMS symptoms across multiple $(>2)$ independent exposures to hypoxia would be useful for predicting AMS on future exposures. Secondly, as with any study with a small to moderate sample size, we also cannot rule out the possibility of type I errors. Thirdly, the duration of the exposures were a compromise between feasibility and the typical time course of AMS, and increasing the exposure length may affect the repeatability of AMS. Finally, it is unclear whether our results can be generalized to high altitude settings. Subjects were exposed to normobaric hypoxia instead of hypobaric hypoxia, and the 2 modes of hypoxia may differ in terms of their capacities to induce AMS. ${ }^{43,44}$ Exposure to normobaric hypoxia also requires subjects to 
be confined to a small space that is unfamiliar and potentially uncomfortable, possibly making this mode of hypoxia different from a true altitude exposure. ${ }^{45}$ Similarly, the normobaric hypoxia chamber used in this study was not able to maintain a $\mathrm{CO}_{2}$ concentration equal to the atmospheric concentration of $\mathrm{CO}_{2}$. The higher ambient $\mathrm{CO}_{2}$ would not likely have a large effect on ventilation, ${ }^{46}$ and the repeated measures design and inclusion of a sham condition should have controlled for any effects that the slight hypercapnia would have on the subjects; however, this difference is still a limitation to our study.

\section{Conclusions}

We demonstrated that AMS severity (measured with the LLS questionnaire) was not repeatable in response to 2 identical 12-hour normobaric hypoxia exposures, and that the AMS status on $\mathrm{H} 1$ was not a reliable predictor of the AMS status on $\mathrm{H} 2$. The measured physiological responses to normobaric hypoxia were moderately to strongly repeatable, but none was associated with AMS status. Finally, a greater focus on headache may be warranted in future AMS studies: headache was repeatable across hypoxic conditions, and headache was the only AMS symptom with an elevated severity (relative to sham) on the second hypoxic exposure.

\section{Acknowledgments}

The Natural Sciences and Engineering Research Council of Canada (NSERC) provided funding for this project, and the Canadian Foundation of Innovation (CFI) provided funding for the normobaric hypoxia chamber. Martin J. MacInnis is the recipient of an NSERC Canada Graduate Scholarship.

\section{References}

1. Hackett PH, Roach RC. High-altitude illness. $N$ Engl $J$ Med. 2001;345:107-114.

2. MacInnis MJ, Wang P, Koehle MS, Rupert JL. The genetics of altitude tolerance: the evidence for inherited susceptibility to acute mountain sickness. J Occup Environ Med. 2011;53:159-168.

3. Barry PW, Pollard AJ. Altitude illness. BMJ. 2003;326: 915-919.

4. Nakagawa S, Schielzeth H. Repeatability for Gaussian and non-Gaussian data: a practical guide for biologists. Biol Rev Camb Philos Soc. 2010;85:935-956.

5. Imray $\mathrm{C}$, Booth $\mathrm{A}$, Wright $\mathrm{A}$, Bradwell A. Acute altitude illnesses. BMJ. 2011;343:d4943-d4943.

6. Honigman B, Theis MK, Koziol-McLain J, et al. Acute mountain sickness in a general tourist population at moderate altitudes. Ann Intern Med. 1993;118:587-592.
7. Schneider M, Bernasch D, Weymann J, Holle R, Bartsch P. Acute mountain sickness: influence of susceptibility, preexposure, and ascent rate. Med Sci Sports Exerc. 2002;34:1886-1891.

8. Richalet JP, Larmignat P, Poitrine E, Letournel M, Canoui-Poitrine F. Physiological risk factors for severe high-altitude illness: a prospective cohort study. Am J Respir Crit Care Med. 2012;185:192-198.

9. Robinson SM, King AB, Aoki V. Acute mountain sickness: reproducibility of its severity and duration in an individual. Aerosp Med. 1971;42:706-708.

10. Forster P. Reproducibility of individual response to exposure to high altitude. $\mathrm{Br}$ Med J (Clin Res Ed). 1984;289:1269.

11. Rexhaj E, Garcin S, Rimoldi SF, et al. Reproducibility of acute mountain sickness in children and adults: a prospective study. Pediatrics. 2011;127:e1445-e1448.

12. Aoki VS, Robinson SM. Body hydration and the incidence and severity of acute mountain sickness. J Appl Physiol. 1971;31:363-367.

13. West JB. High-altitude medicine. Am J Respir Crit Care Med. 2012;186:1229-1237.

14. Karinen HM, Peltonen JE, Kähönen M, Tikkanen HO. Prediction of acute mountain sickness by monitoring arterial oxygen saturation during ascent. High Alt Med Biol. 2010;11:325-332.

15. Chen HC, Lin WL, Wu JY, et al. Change in oxygen saturation does not predict acute mountain sickness on Jade Mountain. Wilderness Environ Med. 2012;23:122-127.

16. Loeppky JA, Icenogle MV, Maes D, Riboni K, Scotto P, Roach RC. Body temperature, autonomic responses, and acute mountain sickness. High Alt Med Biol. 2003;4:367373.

17. MacInnis MJ, Rupert JL, Koehle MS. Evaluation of the Balance Error Scoring System (BESS) in the diagnosis of acute mountain sickness at $4380 \mathrm{~m}$. High Alt Med Biol. 2012;13:93-97.

18. Brown DE, Beall CM, Strohl KP, Mills PS. Exhaled nitric oxide decreases upon acute exposure to high-altitude hypoxia. Am J Hum Biol. 2006;18:196-202.

19. MacInnis MJ, Carter EA, Koehle MS, Rupert JL. Exhaled nitric oxide is associated with acute mountain sickness susceptibility during exposure to normobaric hypoxia. Respir Physiol Neurobiol. 2012;180:40-44.

20. Hackett PH. Caffeine at high altitude: java at base camp. High Alt Med Biol. 2010;11:13-17.

21. West JB. Prediction of barometric pressures at high altitude with the use of model atmospheres. J Appl Physiol. 1996;81:1850-1854.

22. Olin AC, Aldenbratt A, Ekman A, et al. Increased nitric oxide in exhaled air after intake of a nitrate-rich meal. Respir Med. 2001;95:153-158.

23. Roach RC, Bärtsch P, Oelz O, Hackett P. Lake Louise AMS Scoring Consensus Committee: the Lake Louise acute mountain sickness scoring system. In: Sutton JR, Houston C, Coates G, eds. Hypoxia and Molecular Medicine Burlington, VT: Queen City Printers; 1993:272-274. 
24. American Thoracic Society, European Respiratory Society, ATS/ERS recommendations for standardized procedures for the online and offline measurement of exhaled lower respiratory nitric oxide and nasal nitric oxide, 2005. Am J Respir Crit Care Med. 2005;171: 912-930.

25. Hemmingsson $T$, Linnarsson D. Lower exhaled nitric oxide in hypobaric than in normobaric acute hypoxia. Respir Physiol Neurobiol. 2009;169:74-77.

26. Kundel HL, Polansky M. Measurement of observer agreement. Radiology. 2003;228:303-308.

27. Taylor DR, Pijnenburg MW, Smith AD, Jongste JCD. Exhaled nitric oxide measurements: clinical application and interpretation. Thorax. 2006;61:817-827.

28. Roach R, Kayser B, Hackett P. Pro: headache should be a required symptom for the diagnosis of acute mountain sickness. High Alt Med Biol. 2011;12:21-22.

29. Muza SR, Kaminsky D, Fulco CS, Banderet LE, Cymerman A. Cysteinyl leukotriene blockade does not prevent acute mountain sickness. Aviat Space Environ Med. 2004;75:413-419.

30. MacNutt MJ, Laursen PB, Kedia S, et al. Acclimatisation in trekkers with and without recent exposure to high altitude. Eur J Appl Physiol. 2012;112:3287-3294.

31. Hackett PH, Rennie D, Levine HD. The incidence, importance, and prophylaxis of acute mountain sickness. Lancet. 1976;2:1149-1155.

32. Windsor JS. Pulse oximetry and predicting acute mountain sickness: are we asking the right questions? Wilderness Environ Med. 2012;23:112-113.

33. Wagner DR, Knott JR, Fry JP. Oximetry fails to predict acute mountain sickness or summit success during a rapid ascent to 5640 meters. Wilderness Environ Med. 2012;23: 114-121.

34. Koehle MS, Guenette JA, Warburton DER. Oximetry, heart rate variability, and the diagnosis of mild-tomoderate acute mountain sickness. Eur J Emerg Med. 2010;17:119-122.

35. Bilo G, Revera M, Bussotti M, et al. Effects of slow deep breathing at high altitude on oxygen saturation, pulmonary and systemic hemodynamics. PLoS ONE. 2012;7:e49074.
36. Erba P, Anastasi S, Senn O, Maggiorini M, Bloch KE. Acute mountain sickness is related to nocturnal hypoxemia but not to hypoventilation. Eur Respir J. 2004;24:303-308.

37. Nespoulet H, Wuyam B, Tamisier R, et al. Altitude illness is related to low hypoxic chemoresponse and low oxygenation during sleep. Eur Respir J. 2012;40:673-680.

38. Stanforth PR, Gagnon J, Rice T, et al. Reproducibility of resting blood pressure and heart rate measurements. The HERITAGE family study. Ann Epidemiol. 2000;10:271-277.

39. Bland JM, Altman DG. A note on the use of the intraclass correlation coefficient in the evaluation of agreement between two methods of measurement. Comput Biol Med. 1990;20:337-340.

40. Donnelly J, Cowan DC, Yeoman DJ, et al. Exhaled nitric oxide and pulmonary artery pressures during graded ascent to high altitude. Respir Physiol Neurobiol. 2011;177:213-217.

41. Kharitonov SA, Gonio F, Kelly C, Meah S, Barnes PJ. Reproducibility of exhaled nitric oxide measurements in healthy and asthmatic adults and children. Eur Respir J. 2003;21:433-438.

42. You H, Li X, Pei T, Huang Q, Liu F, Gao Y. Predictive value of basal exhaled nitric oxide and carbon monoxide for acute mountain sickness. Wilderness Environ Med. 2012;23:316-324.

43. Roach RC, Loeppky JA, Icenogle MV. Acute mountain sickness: increased severity during simulated altitude compared with normobaric hypoxia. J Appl Physiol. 1996;81:1908-1910.

44. Richard NA, Sahota IS, Widmer N, Ferguson S, Sheel AW, Koehle MS. Acute mountain sickness, chemosensitivity, and cardio-respiratory responses in humans exposed to hypobaric and normobaric hypoxia. J Appl Physiol. 2014;116:945-952.

45. Girard O, Koehle MS, MacInnis MJ, et al. Comments on point:counterpoint: hypobaric hypoxia induces/does not induce different responses from normobaric hypoxia. J Appl Physiol. 2012;112:1788-1794.

46. Loeppky JA, Icenogle M, Scotto P, Robergs R, HinghoferSzalkay H, Roach RC. Ventilation during simulated altitude, normobaric hypoxia and normoxic hypobaria. Respir Physiol. 1997;107:231-239. 